\title{
Towards the Organization of Telerehabilitation Services
}

\author{
Gillberto Marzano ${ }^{1 *}$, Anna Pellegrino ${ }^{2}$ \\ ${ }^{1}$ Rezekne Academy of Technologies, Latvia \\ ${ }^{2}$ Udine University, Italy
}

Submission: April 09, 2017; Published: May 10, 2017

*Corresponding author: Gilberto Marzano, Rezekne Academy of Technologies, Latvia, Email: gilberto.marzano@rta.lv

\begin{abstract}
Research has underlined the potential for Information and Communication Technologies (ICT) to improve healthcare services making them more effective and reducing their costs. In the last decade, thanks to the developments in technology,a wide range of ICT-based solutions have been implemented for the rehabilitation of patients and the concept of telerehabilitation is commonly used to refer to the provision of rehabilitation care at a distance. Telerehabilitation, or e-rehabilitation, is now an autonomous discipline and, lately, the notion of social telerehabilitation has been introduced to distinguish the application of ICT to the social rehabilitation sphere. This article aims at illustrating the major challenges that arise in the implementation and delivery of effective and sustainable telerehabilitation services. In this regard, organizational aspects represent a crucial factor, since the development of effective telerehabilitation services is not only a question of technology. Much depends on appropriate organization models that include additional management procedures as well as new criteria for the acceptance of telerehabilitation treatments.
\end{abstract}

\section{Introduction}

Telerehabilitation has a short history as an autonomous discipline. The term telerehabilitation appears for the first time in literature at the end of 1990s designingthe use of Information and CommunicationsTechnologies (ICT) to provide rehabilitation and long-term support to people with disabilities [1].

In the last few years, telerehabilitationis getting out of its infancy and telerehabilitaton solutions have been successfully experimented in many areas [2-4], particularly that of rehabilitation following traumatic injury. Literature is rich of applications realized for assessment, physical therapy, monitoring, and improving the quality of life of patients after stroke [5].

Telerehabilitation, or e-rehabilitation. was considered at the beginning a subcomponent of the broader area of telemedicine [6] but now is an autonomous discipline and, lately, the notion of social telerehabilitation has been introduced to distinguish the application of ICT to the social rehabilitation sphere [7].

Literature widely argues the advantages of telerehabilitation in the treatment of patients. Telerehabilitation services are considered as being a cost-effective alternative to traditional rehabilitation services since they can be delivered at a distance, thus reducing the travel costs and difficulties for patients to receive care at a healthcare facility.
The increasing interest in telerehabilitation is closely related to the diffusion of the internet and to the idea, widely shared, that ICT can give the means to realize more effective and accurate as well as cheaper and more powerful services.

This article focuses on the challenges we have to face in implementing telerehabilitation services. It aims at stimulating the debate on the institutionalization of telerehabilitation services and highlights some questions emerged in an ongoing research where we are evaluating the sustainability of telerehabilitation services for elderly. The central question of our investigation is: under which conditions can telerehabilitation services become a practical and sustainable alternative for dispensing large-scale rehabilitation services to elderly persons?

Indeed, telerehabilitation is still in an early stage and the sustainability of large-scale telerehabilitation services is a complex problem $[8,9]$.

By the way, our opinion is that to turn from experimentation to actual telerehabilitation services we need to carefully evaluate many contextual factors both technical and organizational. Although the recent technological advances are introducing new opportunities to overcome the limitations of the traditional computer-based approach [10], the transition towards telerehabiliation services doesn't appear so simple. 


\section{The Telerehabilitation Revolution}

Currently, the telerehabilitationapplications encompass four main healthcare areas:

A. Control at distance of patients and medical devices.

B. Computer-assisted rehabilitation exercises (physical and cognitive).

C. Communication between patients, doctors, and caregivers.

D. Distance training, either for patients or medical personnel.

Forecasts by Goldman Sachs put the total value of the US telerehabilitation market at $\$ 32.4$ billion, of which $45 \%$ derives from remote patient monitoring; $37 \%$ from telehealth; and $18 \%$ from behavioural modification. Chronic disease management falls entirely within remote patient monitoring. At present, total revenue is estimated in the several hundred million, with a wide range of company performance, ranging from as low as $\$ 5$ million to just under $\$ 100$ million (Table 1 ).

Table 1: Potential economic impact of ICTs on the healthcare market (source: Goldman Sachs Global Investment Research, 2015).

\begin{tabular}{|c|c|c|c|}
\hline Vertical & Disease State & $\begin{array}{c}\text { Total Savings } \\
\text { Opportunity }\end{array}$ & $\begin{array}{c}\text { Commercial } \\
\text { Opportunity }\end{array}$ \\
\hline $\begin{array}{c}\text { Remote patient } \\
\text { monitoring }\end{array}$ & $\begin{array}{c}\text { Heart disease, } \\
\text { COPD/Asthma, } \\
\text { Diabetes }\end{array}$ & $\$ 200$ +billion & $\sim \$ 15$ billion \\
\hline Telehealth & $\begin{array}{c}\text { Routine \& } \\
\text { psychological } \\
\text { care }\end{array}$ & $\$ 100+$ billion & $\sim \$ 12$ billion \\
\hline $\begin{array}{c}\text { Behavior } \\
\text { modification } \\
\text { smoking, } \\
\text { cessation, } \\
\text { overall } \\
\text { life style } \\
\text { improvement }\end{array}$ & $\begin{array}{c}\text { indefinitely } \\
\text { charge }\end{array}$ & $\sim \$ 6$ billion \\
\hline
\end{tabular}

In the last few years, we assisted to a new emerging strand of telerehabilitation: this is the wearable technology. Thanks to the miniaturisation of electronic components, many types of wearable devices have been developed for applications in health and wellbeing, such as the Apple's HealthKit and Google Fit. The application of wearable technology to monitor older adults and subjects with chronic conditions at home and in community settings is multiplying, while the integration of wearable and ambient sensors has made significant progress [11]. In the logic of the Internet of Things - namely the interaction not only with persons (social networks) or with electronic intelligent agents (semantic Web) but also with things -the new health sensors are smart, since they are able to connect with other devices and share data.

Another very popular telerehabilitation sector is related to gamification, namely the use of game elements in nongame contexts. The idea lies inusing elements from games in a telerehabilitation treatment to motivate patients in order to perform repetitive exercises [12].

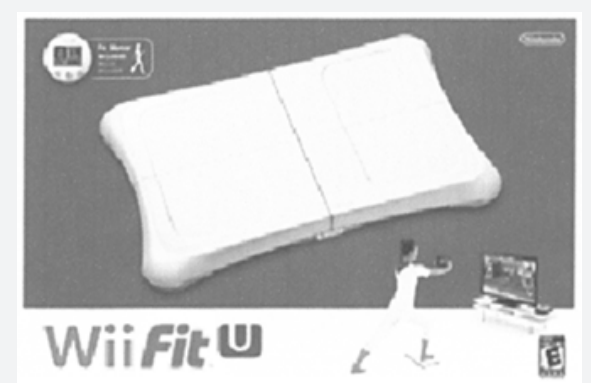

Figure 1: The Nintendo balance board (cost about $\$ 30.00$ ).

In this regard, a large number oftelerehabilitation experiments have been made based on the Nintendo Wii platform (Figure 1) and although Nintendo confirmed that it had discontinued production of the Wii in Japan and Europe, the literature shows that Wii experimentations continued in 2016.

Recently, the same Microsoft has entered into the telerehabilitation sector with their Kinect motion sensor, originally for the Xbox 360, which was developed to create an active and immersive gaming experience (Figure 2). Kinect technology enables users to control and interact with their consoles using gestures and spoken commands and provides a human skeletal tracking system that can be used for musculoskeletal health exercises. Kinect includes an SDK (software development kit), APIs (Application Program Interface), and tools to develop customised solutions.

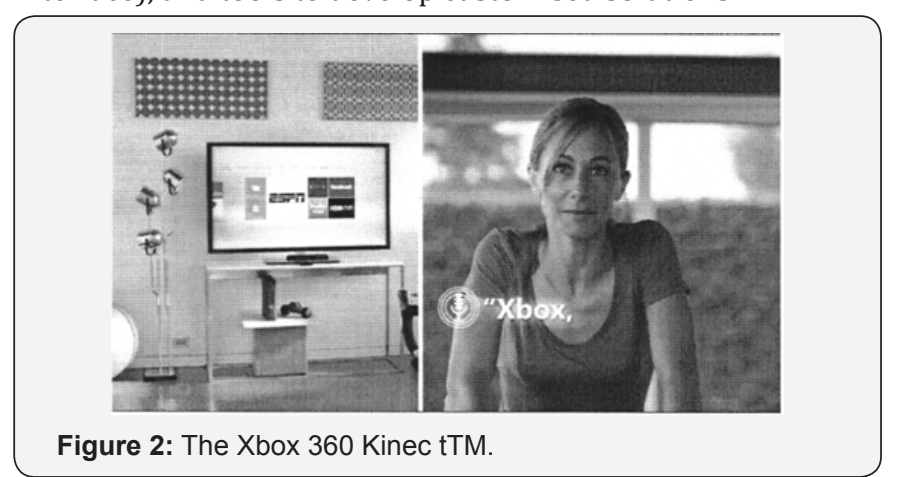

Although it is a common opinion thatcommercial game systems present some serious shortfalls, due to the omission of medical considerations during their development, commercial game continue to be popular in telerehabilitation because of their low cost and the elevated level of usability. Of course, the current applications based on commercial systems present manylimitations, e.g.they lack the adaptation and integration necessary to fit the heterogeneous nature of treatments.

However, the most interesting advancement in telerehabilitationis represented by robots. Their application to rehabilitation treatments constitutes a newfrontier. Usually, rehabilitation robots are physically assistive devices whose primary function is not communicative, and which are not perceived by patients as social entities. However, there are new 
robots that can establish therapeutic human relationships, for example in the context of occupational therapy and the treatment of Parkinson's or Alzheimer's disease [13].

\section{Challenges in Implementing Telerehabilitation Services}

We can distinguish between technological and organizational challenges.

In implementing telerehabilitation services, device integration and data integration represent the main technical issues. Device integration is necessary to integrate the various sensors and equipment involved in a telerehabilitationservicewhilst data integration is needed to providetelerehabilitationapplications with a unified method to access and process heterogeneous data sources. Approaches to data integration can encompass ontologies or data annotations using common controlled vocabularies as well as graph-based solutions [14].

Consider the case in which you aim at monitoring a patient during their exercises using an equipment based on an electronic force platform, sensors, and cameras. Of course,yourapplication not only should integrate data transmitted from different sourcesbut shouldalso provide data validation as well as check that sensors are working properly. This implies the interoperability of different mechanisms, devices, and equipment, e.g.those that measure blood pressure, pulse, and the patient's movements. Moreover, some data could be the result of multiple data processing operations. For example, the analysis of the patient's movement could require the combination of data from inertial sensors and ultrasonic or optical tracking systems [15]. Other limitations are:

A. Unwieldy wires between sensors and a processing unit.

B. Interference on a wireless communication channel shared by multiple devices.

C. Nonexistent support for massive data collection and knowledge discovery [16].

However, in implementing telerehabilitation services, you have also to tackle organizational issues. A telerehabilitation service is something more than the delivery of a treatment at a distance. It includes procedures to access the service as well asthe definition of rigorous service level agreements and evaluation criteria.

Moreover, an aspect that should not be undervalued is the education of telerehabilitation staff and users. Both the personnel and users should be properly trained and motivated.

All the above issues arise especially for telerehabilitation services that involve computer-assisted rehabilitation exercises (physical and cognitive).

Finally, there is an important aspect that can affect the effectiveness of home treatments. What is the influence of the environment on the results of a treatment? In other words, how does the home environment affect the treatments?

The home environment includes both physical spaces and familiar relationships and there aren't investigations on the influence of these factors on the telerehabilitation treatments, at the moment.

\section{Discussion}

Control at a distance includes solutions for monitoring patients by combining clinical observations with data from wearable sensors as well as the use of live interactive video.

Furthermore, medication reminders can be integrated in automatic pill dispensers whilst sensor-embedded pills and a patch placed on the patient's body can gain information to deal with complex and chronic conditions, e.g. tracking when the patient swallows the medication.

Recent advances in hardware, and more specifically sensor technologies, allow us to acquire accurate information of human behaviors and activities in daily life environments. This fact has attracted the attention of a high number of researchers from very different knowledge areas, such as computer science, biomechanics, or medical and health care, among others. The main result of the project is a medical information system equipped with an Ambient Intelligence module to assist physiotherapists in managing and assessing diagnosis tests carried out by patients. The resulting information system, called PReSenS (Proactive Rehabilitation Sensing System), aims at improving automatic evaluation of physical activity in medical environments, and at providing healthcare experts with a tool to acquire and analyze motion data using marker-free solutions such as depth sensor cameras.

In a first stage, the physiotherapist saves exercise templates using the healthcare front-end. This template is stored into a remote database containing the information about exercises, patient plans and patient performances. Then, he/she proposes an exercise plan to the patient, who performs the exercises remotely in Stage 2. The system is able to provide the patient with a preliminary and automatic evaluation of the plan execution, and stores this information into the remote database. Finally, in Stage 3, both patients and physiotherapists can access the system remotely using a web front-end, to make an in-depth signal motion analysis, to obtain healthcare experts suggestions, professional evaluations and plan modifications. According to this description, we may distinguish three main application front-ends: The healthcare expert front-end, aimed for exercise template definition and learning, and patient exercise plan; the patient front-end, used for execution of exercise plans and performance evaluation of patients; and the web interface, to visualize exercise templates, exercise performance of patients, and to access all system information online. In addition, we also 
distinguish a database server to access and store exercise data remotely. Both the healthcare expert and patient front-ends are platform-dependent desktop applications, which require the depth sensor to acquire user motion data. On the other hand, the web view is platform independent and its use is focused on information management and access to both exercises and patient information.

\section{Conclusion}

Although telerehabilitation currently represents a very promising field, many questions still remain open, for which concrete and reliable answers are required.

However, it seems the moment to move from experimentation to the operational analysis of telerehabilitation services focusing on new delivery models.

In this regard, hybrid models for telerehabilitation services should be evaluated in order toprovide transition solutions based onlocal rehabilitation centers controlled and managed remotely. Patients could use these local center to access treatments at a distancesupervised by specialists. These centers could employ personnel that helps patients in the use of technologies. The introduction of an intermediation level could facilitate the upscaling of telerehabilitation services.

The first step in this direction could be to establish telerehabilitationcenters at nursing homes for elderly people. In this case, the tangible benefits would be the reduction of staff costs and a more accurate patient monitoring.

Above all, in defining the new telerehabilitation services, you must start to create new evidence-based organizational models.

\section{References}

1. Burns RB, Crislip D, Daviou P, Temkin A, Vesmarovich S, et al. (1998) Using telerehabilitation to support assistive technology. Assist Technol 10(2): 126-133

2. Morone G, Tramontano M, Iosa M, Shofany J, Iemma A, et al. (2014) The efficacy of balance training with video game-based therapy in subacute stroke patients: a randomized controlled trial. BioMed research international 2014(2014): 6
3. Levin MF, Weiss PL, Keshner EA (2015) Emergence of virtual reality as a tool for upper limb rehabilitation: incorporation of motor control and motor learning principles. Phys Ther 95(3): 415-425.

4. Kairy D, Veras M, Archambault P, Hernandez A, Higgins J, et al. (2016) Maximizing post-stroke upper limb rehabilitation using a novel telerehabilitation interactive virtual reality system in the patient's home: study protocol of a randomized clinical trial. Contem clin Trials 47: 49-53.

5. Linder SM, Rosenfeldt AB, Bay RC, Sahu K, Wolf SL, et al. (2015) Improving quality of life and depression after stroke through telerehabilitation. Am J Occup Ther 69(2): 1-10.

6. Lai JCK, Woo J, Hui E, Chan WM (2004) Telerehabilitation - a new model for community-based stroke rehabilitation. J Telemed Telecare 10(4): 199-205.

7. Marzano G (2017) Social telerehabilitation, Encyclopedia of Information Science and Technology. ( $4^{\text {th }}$ edn), IGI Global, USA.

8. Merrell R C, Doarn CR (2012) Barriers and barricades, Telemedicine and e-Health 18(2): 79-8.

9. Wade VA, Taylor AD, Kidd MR, Carati C (2016). Transitioning a home telehealth project into a sustainable, large-scale service: a qualitative study. BMC health services research 16(1): 183.

10. Pravettoni G, Folgieri R, Lucchiari C (2015) Cognitive science in telemedicine: from psychology to artificial intelligence. Tele-oncology 5-22.

11. Patel S, Park H, Bonato P, Chan L, Rodgers M (2012) A review of wearable sensors and systems with application in rehabilitation. J Neuroeng Rehabil 9(1): 5-21.

12. Dithmer M, Rasmussen JO, Grönvall E, Spindle H, Hansen J, et al. (2016) The Heart Game: Using Gamification as Part of a Telerehabilitation Program for Heart Patients. Games Health j 5(1): 27-33.

13. Salichs MA, Encinar IP, Salichs E, Castro-González Á, Malfaz M (2016) Study of scenarios and technical requirements of a social assistive robot for alzheimer's disease patients and their caregivers. International Journal of Social Robotics 8(1): 85-102.

14. Petermann A, Junghanns M, Müller R, Rahm E (2014) Graph-based data integration and business intelligence with BIIIG. Proceedings of the VLDB Endowment 7(13): 1577-1580.

15. Foxlin E, Wormell D, Browne TC, Donfrancesco M (2014) Motion tracking system and method using camera and non-camera sensors : US Patent No. 8,696,458. Washington, USA.

16. Jovanov E, Milenkovic A, Otto C, De Groen PC (2005) A wireless body area network of intelligent motion sensors for computer assisted physical rehabilitation. J Neuroeng Rehabil 2(1): 6.

This work is licensed under Creative Commons Attribution 4.0 License
Your next submission with Juniper Publishers will reach you the below assets

- Quality Editorial service

- Swift Peer Review

- Reprints availability

- E-prints Service

- Manuscript Podcast for convenient understanding

- Global attainment for your research

- Manuscript accessibility in different formats

( Pdf, E-pub, Full Text, Audio)

- Unceasing customer service

Track the below URL for one-step submission https://juniperpublishers.com/online-submission.php 